\title{
Prevalence and Severity of Preoperative Disabilities in Iranian Patients With Radiculopathy From Cervical Disc Herniation
}

\author{
Farzad Omidi-Kashani $^{1{ }^{*}}$; Ali Parsa ${ }^{1}$; Lida Jarahi $^{2}$; Shahrzad Sepidbar ${ }^{1}$ \\ ${ }_{1}^{1}$ Orthopedic Research Center, Department of Orthopedic, Faculty of Medicine, Imam Reza Hospital, Mashhad University of Medical Sciences, Mashhad, Iran \\ 2 Addiction Research Center, Faculty of Medicine, Mashhad University of Medical Sciences, Mashhad, Iran \\ ${ }^{*}$ Corresponding author: Farzad Omidi-Kashani, Orthopedic Research Center, Department of Orthopedic, Faculty of Medicine, Imam Reza Hospital, Mashhad University of Medical \\ Sciences, Mashhad, IR Iran. Tel: +98-5137646500, Fax: +98-5138595023, E-mail: omidif@mums.ac.ir
}

Received: March 21, 2014; Revised: June 5, 2014; Accepted: August 6, 2014

\begin{abstract}
Background: Patients with cervical disc herniation $(\mathrm{CDH})$ may present axial neck pain, radiculopathy, myelopathy separately or all these outcomes together.

Objectives: This study aimed to evaluate the prevalence and severity of preoperative disabilities in Iranian patients with radiculopathy from $\mathrm{CDH}$ and compared these patients with those from other countries.

Patients and Methods: In this retrospective study, medical records (including demographic characteristics, preoperative clinical presentations, and neck disability index score (NDI)) of the 93 patients (42 female, 51 male) with a mean age of $42.7 \pm 9.5$ (ranged; $23-71$ years old) who had underwent surgery due to radiculopathy from cervical disc herniation between March 2009 and December 2013 in our orthopedic department were studied. Chi-square, Mann-Whitney, and Kruskal-Wallis tests were used to compare and correlate the variables.

Results: The most common symptoms of our patients included pain (95.7\%) and paresthesia (79.6\%), while a positive Spurling test was the most common sign (68.8\%). The mean NDI in our patients was $47.30 \% \pm 12.81 \%$ (ranged; $28-66 \%$ ) and the most common type of disability was severe disability. We could not find any significant correlation between NDI and sex, age, level or number of herniated discs but as the patient's age increased, the probability of multilevel disc involvement also increased.

Conclusions: Iranian patients with CDH usually consented to surgery while they had severe disability. In comparison with developed countries, it seems that Iranian patients with $\mathrm{CDH}$ present too late to be treated effectively.
\end{abstract}

Keywords:Disability Evaluation; Radiculopathy; Hernia

\section{Background}

Patients with cervical disc herniation (CDH) may present axial neck pain, radiculopathy, myelopathy or all these together (1). As long as the chief complaint of the patient is axial neck pain, surgery is less recommended and these cases are better candidates for conservative strategies unless they are completely resistive $(1,2)$. Cervical disc herniation induced radiculopathy frequently occurs in the patients younger than 55 years, while the disease in older patients is commonly known as cervical spinal stenosis and is comprised of associated pathologies in ligamentum flavum, facet joint, uncovertebral joint or vertebral endplate (3). Cervical radiculopathy from disc herniation may be unilateral or bilateral and associated with sensory, motor or deep tendon reflex abnormalities $(4,5)$.

Similar to lumbar disc herniation, most cases with radiculopathy from $\mathrm{CDH}$ are also cured with conservative measures (6-8). Surgery can be suggested for those patients with refractory radicular complaints not amenable to six to twelve weeks of aggressive non-operative strategies to alleviate uncomfortable pain $(2,6)$. Surgical in- tervention is also recommended for radiculopathy cases presenting a progressive or disabling motor deficit (9). It is strongly recommended that in preoperative study of the patients with suspected radiculopathy from $\mathrm{CDH}$, electro diagnostic evaluation should be included to rule out other pathologies with similar clinical presentation (like carpal tunnel syndrome, brachial plexus injuries and etcetera) (10).

It seems that preoperative severity of disabilities in the patients with radiculopathy from $\mathrm{CDH}$ is not the same in different countries and this difference may be due to the several causes; such as percentage of insurance coverage, cultural differences, economic variations or presence of superstitious beliefs among various communities.

\section{Objectives}

This study aimed to evaluate the prevalence and severity of preoperative disabilities in Iranian patients with radiculopathy from $\mathrm{CDH}$ and compared these patients with those from other countries. 
Omidi-Kashani F et al.

\section{Patients and Methods}

In this retrospective study, after gaining approval from the institutional review board (cone number 910872), medical records of patients, who had underwent surgery due to radiculopathy from cervical disc herniation between March 2009 and December 2013 in our orthopedic department, were studied. Our inclusion criteria included radiculopathy due to one, two or three levels of cervical disc herniation that had been treated with anterior cervical discectomy or corpectomy (Figure 1), and presence of appropriate indications for surgery (refractory radicular complaints to more than six weeks of aggressive conservative treatment, or significant neurological deficits especially if progressive). We excluded cases with revision surgeries, existence of significant underlying disease (such as uncontrolled diabetes mellitus, autoimmune disease and etcetera), unsuitable psychological status, and cervical spinal stenosis not merely due to disc herniation (presence of osteophyte, facet joint hypertrophy, ligamentum flavum hypertrophy and buckling, excessive kyphotic alignment, and etcetera). As the patients with cervical disc herniation induced myelopathy constitute a separate entity with completely different clinical presentation, we also excluded them from our study.

In all the included cases, medical records were evaluated completely and demographic characteristics and preoperative clinical presentations including symptoms and signs were considered. Preoperatively, the severity of disability was evaluated by the neck disability index (NDI) questionnaire. This questionnaire is one of the most commonly used functional outcome tools for cervical related disabilities. This outcome measurement tool is tremendously reliable and was formed by adjusting the Oswestry disability index (11). The questionnaire has been designed to allow the physician to realize how much the neck problem has influenced the patient's capability to deal with activities of daily life. This form consists of 10 questions; each has six possible answers scored from zero (the least disability) to five (the most severe disability). The patient should mark only one choice which strongly describes his/her problem at the time. The total score is multiplied by two and the result is expressed as a percentage. A score of 0 to $8 \%$ indicates no disability, while scores of $10-28 \%, 30-48 \%, 50-68 \%$, and 70-100\% represent mild, moderate, severe disability and completely disabled, respectively.

\subsection{Statistical analysis}

Statistical Package for Social Science (SPSS) version 16 for windows (SPSS Inc. Chicago, IL, USA) was used for statistical analysis. Chi-square, Mann-Whitney and Kruskal-Wallis tests were used to compare and correlate the variables in appropriately indicated points. For all the statistics, $\mathrm{P}<0.05$ was considered significant.

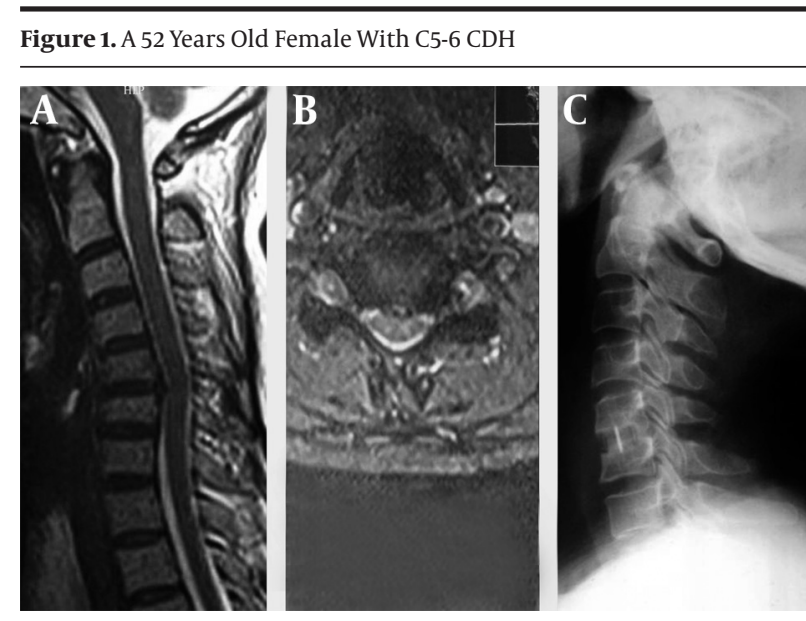

She presented with left arm pain and paresthesis of the lateral surface of forearm for eight months.

NDI score was 58\%. A and B are preoperative sagittal and axial T2 weighted magnetic resonance imaging scans of this patient that show left sided C5-C6 disc herniation with loss of cervical kyphosis. C shows postoperative lateral view of the cervical spine two years after anterior cervical discectomy and fusion with polyetheretherketone (PEEK) cage.

\section{Results}

We treated 93 patients ( 42 female, 51 male) with mean age of $42.7 \pm 9.5$ (ranged; $23-71$ years old). The mean number of disc herniation per case was $1.4 \pm 1.05$ (ranged 1-3). The prevalence of one, two, and three-disc involvement was $57(61.3 \%), 32(34.4 \%)$ and $4(4.3 \%)$, respectively. The prevalence of cervical level of disc herniation (from top to bottom) was as below: $\mathrm{C} 5-6$ in 64 patients (68.8\%), C6-7 in 53 (57.0\%), C4-5 in 15 (16.1\%), and C3-4 in one patient (1.1\%). Clinical presentations (including symptoms and signs) of our patients are summarized in Table 1 . The most common type of disability among our treated patients was severe disability. The association between this and other types of disabilities and the patients' sex ratio is shown in Table 2. According to the Mann-Whitney test, there was no significant correlation between NDI and sex $(P=0.234)$. The mean NDI in our patients was $47.30 \% \pm 12.81 \%$ (ranged; $28-66 \%$ ). According to this questionnaire, prevalence of each item was calculated and presented in Table 3. Our results show that there was no significant relationship between NDI and age of the patients or between NDI and number of herniated discs ( $\mathrm{P}=0.68$ and $\mathrm{P}=0.351$, respectively), yet as the patient's age increased, the probability of multilevel disc involvement also increased (correlation coefficient $=0.544$ and $\mathrm{P}=0.002$ ). Based on the Kruskal-Wallis test, there was no relationship between the level of herniated disc and severity of disability $(\mathrm{P}=0.674)$. 
Table 1. Preoperative Presentation of the Patients with $\mathrm{CDH}$ Induced Radiculopathy ${ }^{\mathrm{a}}$

\begin{tabular}{lc}
\hline Clinical Presentation & Prevalence \\
\hline Symptoms & \\
Arm pain & $89(95.7)$ \\
\hline Left-sided chest and arm pain (cervical angina) & $2(2.2)$ \\
\hline Neck Pain & $76(81.7)$ \\
\hline Scapular pain & $41(44.1)$ \\
\hline Anterior chest pain & $21(22.6)$ \\
\hline Pain in head (headache) & $13(14.0)$ \\
\hline Paresthesis & $74(79.6)$ \\
\hline Signs & $43(46.2)$ \\
\hline Muscular weakness & $62(66.7)$ \\
\hline Reflex abnormalities & $64(68.8)$ \\
\hline Positive Spurling test & $47(50.5)$ \\
\hline Positive shoulder abduction relief sign 50.5 & $38(40.9)$ \\
\hline Positive distraction test & \\
\hline a Data are presented as No.(\%).
\end{tabular}

Table 2. Prevalence of NDI Scoring in Our Patients ${ }^{a}$

\begin{tabular}{lccc}
\hline Degree of Disability & \multicolumn{3}{c}{ Prevalence } \\
\cline { 2 - 4 } & Male & Female & Total \\
\hline No disability & 2 & 1 & $3(3.2)$ \\
Mild disability & 8 & 8 & $16(17.2)$ \\
Moderate disability & 15 & 11 & $26(28.0)$ \\
Severe disability & 20 & 15 & $35(37.6)$ \\
Completely disabled & 6 & 7 & $13(14.0)$ \\
\hline
\end{tabular}

${ }^{\mathrm{a}}$ Data are presented as No. or No. (\%).

\section{Discussion}

Apparently, consent to surgery is not the same throughout the world. In this study, we found that Iranian patients with cervical disc herniation, refused to be operated unless they had become severely disabled. Although, our knowledge of $\mathrm{CDH}$ denotes that most of these cases heal gradually without any operation, it has been proven that in appropriately indicated patients surgery would be associated with satisfactory outcomes (6).

In the study conducted by Henderson et al, they evaluated 736 patients with $\mathrm{CDH}$ (12). In their study, the most prevalent clinical presentations were arm pain (99\%); sensory deficit (85\%), neck pain (80\%), reflex deficit (71\%), muscular weakness (68\%) and scapular pain (52\%). They noted that Spurling test and shoulder abduction relief sign were positive in a large percentage of their patients yet they did not declare the exact prevalence. Similarly, in our patients pain was the most prevalent symptom followed by, sensory deficit, reflex abnormalities, and muscular weakness, in decreasing order. In our study, the prevalence of Spurling, shoulder abduction relief sign, and distraction tests was $68.8 \%, 50.5 \%$, and $40.9 \%$, respectively.

In another study, Kelly et al. specifically analyzed the effect of $\mathrm{CDH}$ and its surgical treatment on driving ability (13). About $50 \%$ of patients reported moderate or severe disability during preoperative driving. As soon as six weeks after surgery (either anterior cervical discectomy and fusion or total disc arthroplasty) this disability improved to no or little disability and lasted throughout the follow-up. The author concluded that although radiculopathy or myelopathy from $\mathrm{CDH}$ can limit driving ability, after appropriate surgical treatment, most patients are able to return to contented driving at six weeks.

Table 3. Prevalence of Different Disability Items (According to Neck Disability Index) in Our Patients

\begin{tabular}{lcccccc}
\hline NDI Items & \multicolumn{7}{c}{ Score (\%) } \\
\cline { 2 - 7 } & $\mathbf{0}$ & $\mathbf{1}$ & $\mathbf{2}$ & $\mathbf{3}$ & $\mathbf{4}$ & $\mathbf{5}$ \\
\hline Pain Intensity & $12(12.9)$ & $17(18.3)$ & $13(14.0)$ & $15(16.1)$ & $13(14.0)$ & $23(24.7)$ \\
Personal Care & $16(17.2)$ & $25(26.9)$ & $18(19.4)$ & $22(23.7)$ & $6(6.5)$ & $6(6.5)$ \\
Lifting & $4(4.3)$ & $18(19.4)$ & $4(4.3)$ & $19(20.4)$ & $24(25.8)$ & $24(25.8)$ \\
Reading & $9(9.7)$ & $19(20.4)$ & $15(16.1)$ & $29(31.2)$ & $9(9.7)$ & $12(12.9)$ \\
Headache & $39(41.9)$ & $25(26.9)$ & $17(18.3)$ & $7(7.5)$ & $3(3.2)$ & $2(2.1)$ \\
Concentration & $34(36.6)$ & $16(17.2)$ & $25(26.9)$ & $11(11.8)$ & $4(4.3)$ & $3(3.2)$ \\
Work & $13(14.0)$ & $6(6.5)$ & $31(33.3)$ & $18(19.4)$ & $4(4.3)$ & $21(22.6)$ \\
Driving & $7(7.5)$ & $19(20.4)$ & $9(9.7)$ & $16(17.2)$ & $24(25.8)$ & $18(19.4)$ \\
Sleeping & $25(26.9)$ & $18(19.4)$ & $14(15.1)$ & $9(9.7)$ & $18(19.4)$ & $9(9.7)$ \\
Recreation & $4(4.3)$ & $27(29.0)$ & $16(17.2)$ & $6(6.5)$ & $28(30.1)$ & $12(12.9)$ \\
\hline
\end{tabular}


In our study, the prevalence of moderate or severe driving disability was $62.4 \%$ (58 patients). This difference may indicate the delayed reference of the patients or may be a sign of surgical fear among our patients.

Ren et al. in a prospective, consecutive series study evaluated the efficacy of cervical disc replacement in 45 Chinese patients with CDH (14). Contradictory to our study, they not only assessed the patients with radiculopathy, but also patients with myelopathy. The mean preoperative NDI in their study was $43.5 \%$, which is somewhat lower than that of our study (47.3\%). In another recent study by Kim from South Korea, the researchers retrospectively evaluated the surgical outcome of anterior microforaminotomy in 135 patients with $\mathrm{CDH}$ (15). In this study, preoperative NDI score was similar to our study (49.0\%, ranged; 14 to 92\%). These studies comes from Asian counties, yet studies from more developed countries usually point out much earlier presentation and easier patient consent to surgery. For example, in the study carried out by Jagannathan in Virginia, USA, the surgical result of single level posterior cervical foraminotomy in 162 cases was evaluated (16). The mean preoperative NDI score was reported as 36\% (ranged; $4-78 \%$ ), while pain and weakness were the most common presenting symptoms. These significant differences between levels of preoperative NDI scores in different countries may be the result of several underlying factors such as economic level, insurance coverage, and existence of superstitious beliefs in different societies about surgical procedures and so on. These differences will certainly influence the time of patients' presentation and their consent to surgery.

Although our study was performed on a relatively large number of patients, it certainly has some weaknesses. It was an isolated descriptive study and did not assess interferences (such as anterior cervical discectomy, arthroplasty or etcetera) and such studies are definitely worth less than interventional studies; yet we studied a particular aspect of the matter that had not been discussed in detail previously. To verify the effectiveness of these underlying factors on the time of presentation and the level of patients' consent to surgery, further studies are required in the future. In conclusion, Iranian patients with CDH usually consented to surgery when they had severe disability. These late and severe presentations and treatments may have adverse effects on surgical treatment and this needs to be proven in the future.

\section{Acknowledgements}

The authors would like to thank the Deputy of Research, Mashhad University of Medical Science, for their financial support.

\section{Authors' contributions}

Study concept and design: Farzad Omidi-Kashani, Ali Parsa. Analysis and interpretation of data: Ali Parsa, Lida Jarahi, Shahrzad Sepidbar. Drafting of the manuscript: Farzad Omidi-Kashani, Ali Parsa, Lida Jarahi. Critical revision of the manuscript for important intellectual content: Farzad Omidi-Kashani, Ali Parsa, Lida Jarahi and Shahrzad Sepidbar. Statistical analysis: Lida Jarahi, Shahrzad Sepidbar.

\section{References}

1. Rao R. Neck pain, cervical radiculopathy, and cervical myelopathy: pathophysiology, natural history, and clinical evaluation. $J$ Bone Joint Surg Am. 2002;84-A(10):1872-81.

2. Wieser ES, Wang JC. Surgery for neck pain. Neuro surg. 2007;60(1):S51-6.

3. Truumees E, Herkowitz HN. Cervical spondylotic myelopathy and radiculopathy. Instr Course Lect. 2000;49:339-60.

4. Connell MD, Wiesel SW. Natural history and pathogenesis of cervical disk disease. Orthop Clin North Am. 1992;23(3):369-80.

5. Abbed KM, Coumans JV. Cervical radiculopathy: pathophysiology, presentation, and clinical evaluation. Neurosurgery. 2007;60(1 Supp11):S28-34.

6. Rao RD, Currier BL, Albert TJ, Bono CM, Marawar SV, Poelstra KA, et al. Degenerative cervical spondylosis: clinical syndromes, pathogenesis, and management. J Bone Joint Surg Am. 2007;89(6):1360-78.

7. Peolsson A, Soderlund A, Engquist M, Lind B, Lofgren $\mathrm{H}$ Vavruch L, et al. Physical function outcome in cervical radiculopathy patients after physiotherapy alone compared with anterior surgery followed by physiotherapy: a prospective randomized study with a 2-year follow-up. Spine (Phila Pa 1976). 2013;38(4):300-7.

8. Mazanec D, Reddy A. Medical management of cervical spondylosis. Neurosurgery. 2007;60(1 Supp1 1):S43-50.

9. Yonenobu K. Cervical radiculopathy and myelopathy: when and what can surgery contribute to treatment? Eur Spine J. 2000;9(1):1-7.

10. Caridi JM, Pumberger M, Hughes AP. Cervical radiculopathy: a review. HSS J. 2011;7(3):265-72.

11. Vernon H, Mior S. The Neck Disability Index: a study of reliability and validity. J Manipulative Physiol Ther.1991;14(7):409-15.

12. Henderson CM, Hennessy RG, Shuey HJ, Shackelford EG. Posterior-lateral foraminotomy as an exclusive operative technique for cervical radiculopathy: a review of 846 consecutively operated cases. Neurosurgery. 1983;13(5):504-12.

13. Kelly MP, Mitchell MD, Hacker RJ, Riew KD, Sasso RC. Singlelevel degenerative cervical disc disease and driving disability: results from a prospective, randomized trial. Global Spine J. 2013;3(4):237-42.

14. Ren X, Wang W, Chu T, Wang J, Li C, Jiang T. The intermediate clinical outcome and its limitations of Bryan cervical arthroplasty for treatment of cervical disc herniation. J Spinal Disord Tech. 2011;24(4):221-9.

15. Kim MH. Clinical and radiological long-term outcomes of anterior microforaminotomy for cervical degenerative disease. Spine (Phila Pa 1976). 2013;38(21):1812-9.

16. Jagannathan J, Sherman JH, Szabo T, Shaffrey CI, Jane JA. The posterior cervical foraminotomy in the treatment of cervical disc/osteophyte disease: a single-surgeon experience with a minimum of 5 years' clinical and radiographic follow-up.J Neurosurg Spine. 2009;10(4):347-56. 